\title{
Effects of species differences on oocyte regulation of granulosa cell function
}

\author{
Jia Yi Lin, Janet L Pitman-Crawford, Adrian H Bibby, Norma L Hudson, C Joy Mclntosh, \\ Jennifer L Juengel ${ }^{1}$ and Kenneth P McNatty \\ School of Biological Sciences, Victoria University of Wellington, Wellington 6140, New Zealand and ${ }^{1}$ Centre for \\ Reproduction and Genomics, Invermay Agricultural Centre, AgResearch Limited, Mosgiel 9053, New Zealand
}

Correspondence should be addressed to K P McNatty; Email: kenneth.mcnatty@vuw.ac.nz

\begin{abstract}
The aims were to investigate whether oocyte-secreted growth factors from a high (i.e. rat) and low (i.e. sheep) ovulation rate species could stimulate ${ }^{3} \mathrm{H}$-thymidine incorporation in granulosa cells (GC) from antral follicles from the same or across species. Denuded oocytes (DO) were co-incubated with GC with or without specific antibodies to growth differentiating factor 9 (GDF9) or bone morphogenetic protein 15 (BMP15). Co-incubations of DO-GC from the same or across species significantly increased thymidine incorporation in GC with increasing numbers of DO. GDF9 immuno-neutralisation reduced thymidine incorporation in rat GC co-incubated with either rat or ovine DO and in ovine GC co-incubated with ovine or rat DO. BMP15 immuno-neutralisation only reduced thymidine incorporation when ovine DO were co-incubated with either ovine or rat GC. Western blotting of oocytes co-incubated with GC identified GDF9 and BMP15 proteins for sheep and GDF9 protein for rats in oocyte lysates and incubation media. With respect to rat BMP15, a promature protein was identified in the oocyte lysate but not in media. Expression levels of $G D F 9$ relative to $B M P 15$ mRNA in DO co-incubated with GC were highly correlated $\left(R^{2}=0.99\right)$ within both species. However, the expression ratios were markedly different for the rat and sheep (4.3 vs 1.0 respectively). We conclude that during follicular development, rat oocytes secrete little, if any, BMP15 and that GDF9 without BMP15 can stimulate proliferation of rat and ovine GC. In contrast, ovine oocytes secrete both BMP15 and GDF9, and both were found to stimulate proliferation in ovine and rat GC.
\end{abstract}

Reproduction (2012) 144 557-567

\section{Introduction}

Recent in vitro studies using recombinant growth differentiation factor 9 (GDF9) and/or bone morphogenetic protein 15 (BMP15) have shown that these growth factors have a greater than additive (i.e. cooperative) effect on thymidine incorporation in granulosa cells (GC; McNatty et al. 2005a, 2005b, Mclntosh et al. 2008, Mottershead et al. 2011). Furthermore, it has been established that these oocytederived growth factors are essential regulators of ovarian follicular growth and ovulation rate (i.e. the number of follicles ovulated during an oestrous or menstrual cycle) (Dong et al. 1996, Galloway et al. 2000, Di Pasquale et al. 2004, Hanrahan et al. 2004, McNatty et al. 2005C, Otsuka et al. 2011). The evidence in sheep and rodents, as in other species such as pig, deer and cow, is that GDF9 and BMP15 mRNA are expressed in oocytes and not in cumulus cells (Crawford et al. 2011, Crawford \& McNatty 2012). Moreover, GDF9 is expressed in oocytes from the primordial stage in both sheep and rodents whereas BMP15 is expressed only from the primary stage of growth. Both genes continue to be expressed in oocytes throughout follicular development (Dube et al. 1998, Jaatinen et al. 1999, Galloway et al. 2000, Shimasaki et al. 2004, Juengel \& McNatty 2005). Immuno-neutralisation studies in sheep show that, in this species, GDF9 and BMP15 are essential for the proliferation of GC during preantral as well as antral follicular development (McNatty et al. 2007, Juengel et al. 2002). Moreover, the expression of GDF9 and BMP15 mRNA remains essentially unchanged during antral follicular growth until shortly after the preovulatory LH surge in sheep and other species (Prochazka et al. 2004, Feary et al. 2007, Crawford et al. 2011, Mester et al. 2011). In rodents, recombinant human BMP15 has been shown to be a potent growth factor when either added to rat GC in vitro (Otsuka et al. 2000, Moore et al. 2003) or over-expressed in mice (McMahon et al. 2008). However, the proregion of mouse BMP15 inhibits the efficient post-translational processing of BMP15 such that under normal physiological conditions the levels of secreted protein are thought to be low (Hashimoto et al. 2005), at least until the preovulatory 
surge of gonadotrophins (Yoshino et al. 2006). Thus, although variations in biologically active levels of GDF9 and/or BMP15 can increase or decrease ovulation rate (Dong et al. 1996, Galloway et al. 2000, Yan et al. 2001, Juengel et al. 2002, McNatty et al. 2007, Otsuka et al. 2011, McIntosh et al. 2012), it has been proposed that it is the physiological levels of secreted BMP15 protein which may be a key difference between animals with a low or high ovulation rate phenotype (McNatty et al. 2004, Moore et al. 2004).

The primary targets of GDF9 and BMP15 action are the cumulus and GC (see Otsuka et al. (2011) for review). One approach to examining the effects of species differences of oocytes on GC is to test the effects of oocytes from a high ovulation rate phenotype against GC from a low ovulation rate phenotype and vice versa. Hitherto, the oocyte-GC co-incubation model has been used extensively to determine the roles of oocytes or oocyte-derived growth factors on the regulation of GC function (Vanderhyden et al. 1992, Lanuza et al. 1998, Otsuka \& Shimasaki 2002, Gilchrist et al. 2004). This model has also been used to test the role of GDF9 from murine oocytes on murine GC using an immunoneutralisation approach with a GDF9-specific MAB (Gilchrist et al. 2004). However, the application of this co-incubation model to evaluate the roles of both BMP15 and GDF9 in different ovulation rate phenotypes has, to our knowledge, not been undertaken hitherto.

The aim of this study was to test in vitro whether a key difference between a low (i.e. sheep) and a high (i.e. rat) ovulation rate species relates, at least in part, to differences in the role of oocytes and their secretions of GDF9 and BMP15 on GC activity. The hypothesis being tested was that while oocytes from rats and sheep would stimulate DNA synthesis and thus cell proliferation in GC from the same species, rat oocytes would not secrete sufficient BMP15 to cooperate with GDF9 to stimulate DNA synthesis in ovine GC. In contrast, sheep oocytes would secrete sufficient levels of both GDF9 and BMP15 to stimulate rat GC. The key endpoints used in these denuded oocyte (DO) and GC in vitro co-incubation studies within and across species were as follows: ${ }^{3} \mathrm{H}$-thymidine incorporation by GC as a marker of DNA synthesis and cell proliferation (Juengel et al. 2006) in the presence or absence of specific antibodies to GDF9 or BMP15; the molecular forms of GDF9 and BMP15 proteins present within, and/or secreted from, oocytes in vitro; and the levels of BMP15 and GDF9 mRNA expression in oocytes co-incubated with GC.

\section{Results \\ Effect of numbers of DO on ${ }^{3} \mathrm{H}$-thymidine incorporation by GC}

There were significant effects of increasing numbers of oocytes on ${ }^{3} \mathrm{H}$-thymidine incorporation by rat or ovine
GC when co-incubated with DO derived from the same species (Fig. $1 \mathrm{~A}$ and $\mathrm{B}$ ). When rat DO were co-incubated with sheep GC (Fig. 2A) or when sheep DO were co-incubated with rat GC (Fig. 2B), there were also significant effects of increasing numbers of oocytes on the mean level of ${ }^{3} \mathrm{H}$-thymidine incorporated by GC.

\section{Effect of GDF9 or BMP15 immuno-neutralisation on ${ }^{3} \mathrm{H}$-thymidine incorporation by GC after co-incubation with DO}

These data are summarised in Fig. 3. All values shown are expressed relative to the fold increase following co-incubation of DO and GC without antibody present (assigned a value of 1 ). The mean ratios for the nonspecific antibody controls were not significantly different from the controls in which no antibody was added. Immuno-neutralisation of GDF9 protein with a GDF9 $M A B$ during co-incubation of rat DO with either rat or ovine GC or of ovine DO with either ovine or rat GC resulted in significant reductions in ${ }^{3} \mathrm{H}$-thymidine incorporation by GC compared with that for the nonspecific antibody (Fig. 3A). Immuno-neutralisation of BMP15 protein following ovine DO co-incubation with either ovine or rat GC showed significantly reduced levels of ${ }^{3} \mathrm{H}$-thymidine incorporation. However, there was no significant change in ${ }^{3} \mathrm{H}$-thymidine incorporation when rat DO were co-incubated with rat or ovine GC (Fig. 3B).
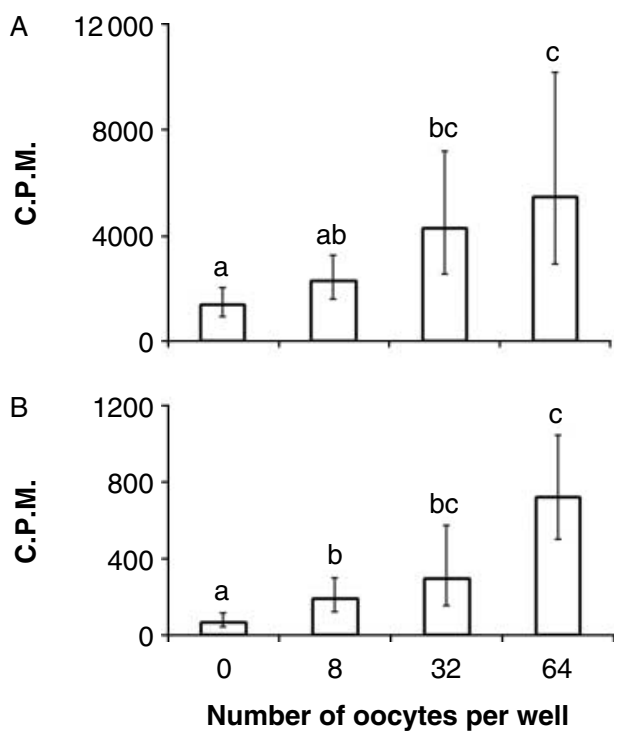

Figure 1 Effects of differing numbers of denuded oocytes (DO) on ${ }^{3} \mathrm{H}$-thymidine incorporation (c.p.m.) by granulosa cells (GC) after co-incubations of $(\mathrm{A})$ rat DO with rat GC or (B) ovine DO with ovine GC. Histograms represent geometric mean $\pm 95 \%$ confidence limits from nine to ten replicate experiments. Histograms not sharing a common alphabetical superscript are significantly different $(P<0.05)$. 

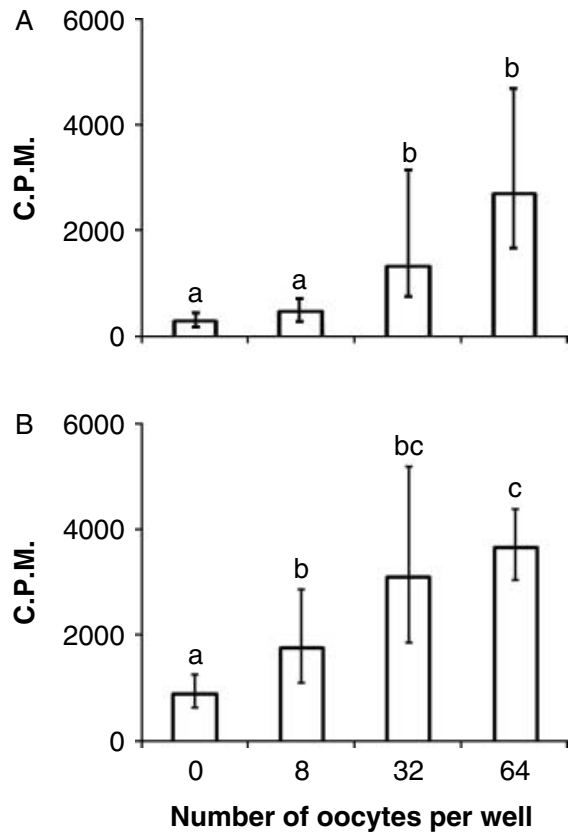

Figure 2 Effects of differing numbers of denuded oocytes (DO) on ${ }^{3} \mathrm{H}$-thymidine incorporation (c.p.m.) by granulosa cells (GC) after co-incubations of $(\mathrm{A})$ rat DO with ovine $\mathrm{GC}$ and (B) ovine DO with rat GC. Histograms represent the geometric mean $\pm 95 \%$ confidence limits from seven to eight replicate experiments. Histograms not sharing a common alphabetical superscript are significantly different $(P<0.05)$.

\section{Effect of BMP15 immuno-neutralisation on ${ }^{3} \mathrm{H}$-thymidine incorporation by $\mathrm{GC}$ after co-incubation with recombinant GDF9 and BMP15}

The ability of the BMP15 antibody (Mab61A) to immunoneutralise recombinant rat (r) BMP15 is shown in Fig. 4. All values shown are expressed relative to the fold increase following co-incubation of recombinant ovine (o) GDF9 + rBMP15 with rat GC (assigned a value of 1). Recombinant oGDF9 or rBMP15 alone did not stimulate ${ }^{3} \mathrm{H}$-thymidine uptake in rat GC above background levels (data not shown). Uptake of ${ }^{3} \mathrm{H}$-thymidine in GC was not different following the addition of a control antibody (PAB1) together with oGDF9 + rBMP15, relative to the addition of recombinant oGDF9+ rBMP15 without antibody $(P>0.05)$. Mab61A significantly suppressed the ability of recombinant oGDF9+ rBMP15 to stimulate ${ }^{3} \mathrm{H}$-thymidine incorporation by GC relative to that of PAB1 antibody $(P<0.01)$.

\section{GDF9 and BMP15 western blotting studies}

To detect the different molecular forms of GDF9 and BMP15 proteins present in oocytes and incubation media, western blotting was performed under reducing conditions. In the rat, mature forms of GDF9 protein were evident in the oocyte lysate and incubation media (Fig. 5A, lanes 1 and 2 respectively). The specificity of these molecular forms of GDF9 was confirmed by blocking studies, where the antibody was preadsorbed with Escherichia coli-derived ovine GDF9 (Fig. 5B, lanes 1 and 2). In sheep, both promature and mature GDF9 protein forms were detected in the oocyte lysate (Fig. 6A, lane 1) and the mature form of GDF9 protein was predominant in the incubation media (Fig. 6A, lane 2). These molecular forms of GDF9 were blocked by preadsorption of the antibody with $E$. coli-derived ovine GDF9 (Fig. 6B). With respect to BMP15, a promature band of $49 \mathrm{kDa}$ size was identified in rat oocyte lysate by two different BMP15 MABs (Fig. 7A, lane 1; C, lane 1). This $49 \mathrm{kDa}$ band was specific for BMP15 as it could be blocked by preadsorption of the antibody with $E$. coli-derived ovine or mouse BMP15 (Fig. 7B and D, lane 1 respectively). With the Mab3A/A, but not 61A, BMP15 antibody trace levels of the mature BMP15 form of the rat BMP15 reference material could be detected but no convincing evidence for a mature form of BMP15 could be detected in the rat oocyte lysate. There was no evidence of the $49 \mathrm{kDa}$ or mature protein band in the incubation media from rat oocytes (data not shown). For ovine BMP15, both a promature
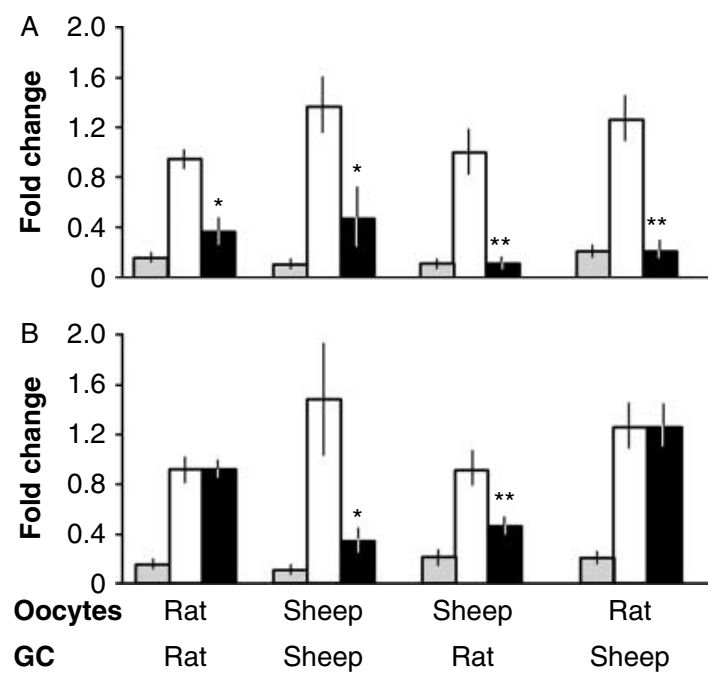

Figure 3 Relative uptake of ${ }^{3} \mathrm{H}$-thymidine by granulosa cells (GC) following co-incubation in the absence of oocytes (A and B; grey histograms), with denuded oocytes (DO; $n=32$ oocytes) in the presence of a MAB against a nematode antigen ( $A$ and $B$ control; white histogram), or with $\mathrm{DO}$ ( $n=32$ oocytes) in the presence of a MAB against GDF9 (A; Mab 47B; black histogram) or against BMP15 (B; Mab $61 \mathrm{~A}$; black histogram). Replicate experimental numbers $(n)$ were as follows: A (rat DO-rat GC, $n=3$; sheep DO-sheep GC, $n=3$; rat DO-sheep GC, $n=5$; rat DO-sheep GC, $n=5$ ) and B: (rat DO-rat GC, $n=5$; sheep DO-sheep GC, $n=9$; rat DO-sheep GC, $n=5$; rat DO-sheep GC, $n=5$ ). Histograms represent the mean fold changes in the antibody treatments compared to those of the control antibody. The median (range) c.p.m. of ${ }^{3} \mathrm{H}$-thymidine taken up by GC following the DO-GC co-incubations without antibody was 1129 (829-1667). The vertical lines represent \pm S.E.M.; ${ }^{*} P<0.05,{ }^{* *} P<0.01$. 


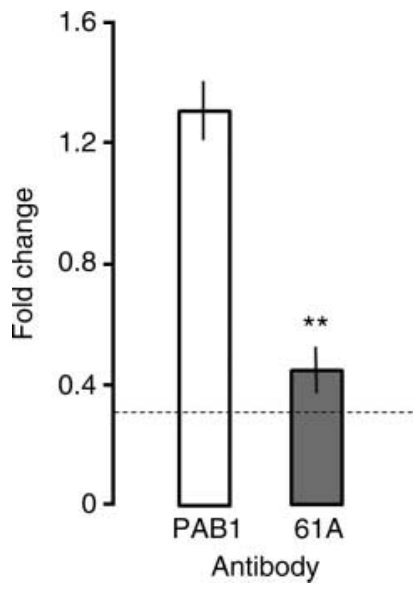

Figure 4 Relative uptake of ${ }^{3} \mathrm{H}$-thymidine by rat granulosa cells (GC) in the presence of recombinant ovine (o) GDF9 plus recombinant rat ( $r$ ) BMP15 with a non-specific MAB PAB1 (MabPAB1) or a MAB to BMP15 (Mab61A). The dotted line indicates the background c.p.m. of ${ }^{3} \mathrm{H}$-thymidine by GC without oGDF9+ rBMP15 relative to wells with oGDF9+ rBMP15 without antibody. The median (range) c.p.m. of ${ }^{3} \mathrm{H}$-thymidine uptake by GC in the oGDF9 + rBMP15 treatment without antibody was 914 (350-1825). $n=4$ experiments. ${ }^{*} P<0.01$.

and a mature form of the protein were present in the oocyte lysate (Fig. 8A, lane 1) whereas only the mature form was noted in the incubation media (Fig. 8A, lane 2). The blocking study using an E. coli-derived ovine BMP15 mature protein confirmed that these protein bands were specific for BMP15 (Fig. 8B, lanes 1 and 2).

\section{BMP15 and GDF9 gene expression in DO during co-incubation with GC}

These data are summarised in Fig. 9. There were no changes in expression levels of Gdf9 and Bmp15 mRNA in rat DO during the first $8 \mathrm{~h}$ of co-incubation with rat GC. However, after 24-h co-incubation, the mean expression levels of both genes had declined by $\sim 75 \%$ $(P=0.050$ for $G d f 9$ and $P=0.052$ for Bmp15) compared with those values at $0 \mathrm{~h}$ (Fig. 9A). When the cycle threshold values for Bmp15 and Gdf9 of individual rat DO were compared over the 0-, 8- and 24-h co-incubation period, a significant linear relationship was identified (Fig. 9B; $P<0.001 ; R^{2}=0.9953$ ). The overall mean Gdf9 mRNA expression level in the rat was $4.32 \pm 0.14$ times that of Bmp15 mRNA. In contrast, the relative expression levels of GDF9 and BMP15 mRNA remained unchanged in ovine $\mathrm{DO}$ throughout the entire co-incubation period with ovine GC (Fig. 9C). When the cycle threshold values for BMP15 and GDF9 mRNA for individual ovine DO were compared over the incubation interval, a significant linear relationship was also identified (Fig. 9D; $P<0.001 ; R^{2}=0.9968$ ). The overall mean GDF9:BMP15 mRNA expression ratio was $1.03 \pm 0.02$.

\section{Discussion}

The key finding from this in vitro study was that the oocyte-derived paracrine signalling system in rats and sheep differs in the way it influences GC activity. Of the two growth factors investigated in this study, namely GDF9 and BMP15, both ovine-secreted factors from the oocyte were required by ovine GC to enhance ${ }^{3} \mathrm{H}$-thymidine incorporation and thus DNA synthesis in vitro. In contrast for the rat, only rat GDF9 was required by rat GC to enhance ${ }^{3} \mathrm{H}$-thymidine incorporation. This is consistent with the in vivo evidence from results in BMP15-KO mice (Yan et al 2001), indicating that BMP15 is not a critical growth factor for follicular development in rodents. Of interest was the finding that rat oocytederived GDF9 without rat BMP15 was able to stimulate ${ }^{3} \mathrm{H}$-thymidine incorporation in ovine GC. Furthermore, both the ovine oocyte-secreted factors GDF9 and BMP15 were essential to stimulate ${ }^{3} \mathrm{H}$-thymidine incorporation in rat GC. These species differences are likely to be due to both the levels of protein secreted and the bioactivity of the different protein forms (McNatty et al. 2005a, 2005b, Simpson et al. 2012).

There was a dose response effect of numbers of ovine or rat oocytes on ${ }^{3} \mathrm{H}$-thymidine incorporation by GC of either species. These findings are consistent with their known roles on ovarian follicular development in vivo (Juengel \& McNatty 2005). Collectively, the aforementioned results are consistent with previous reports showing dose-related effects of mouse, rat or bovine oocytes on ${ }^{3} \mathrm{H}$-thymidine incorporation by rodent GC (Vanderhyden et al. 1992, Lanuza et al. 1998, Otsuka \& Shimasaki 2002, Gilchrist et al. 2004, 2006). Despite a dose response effect of rat oocyte numbers on ${ }^{3} \mathrm{H}$-thymidine incorporation by rat GC, ${ }^{3} \mathrm{H}$-thymidine incorporation in rat DO-GC co-incubations was only reduced after blocking the action of GDF9 and not of BMP15. Moreover, despite rat DO causing at least a

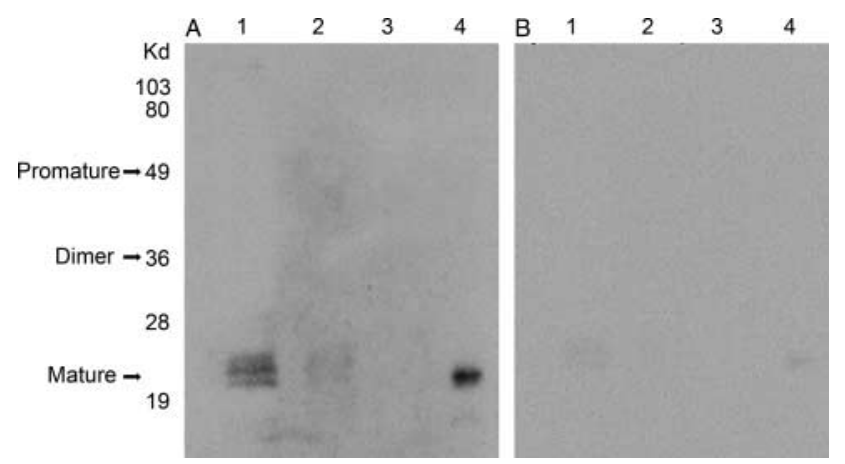

Figure 5 Western immunoblots of GDF9 in (A) rat oocyte lysate and incubation medium and (B) after the GDF9 antibody (Mab47B) was preadsorbed with an E. coli-derived ovine or rat GDF9 mature protein. Molecular sizes are indicated on the left of (A). Lanes are as follows: $1=$ oocyte lysate, $2=$ medium in which oocytes were incubated (incubation medium), $3=$ transfected $293 \mathrm{H}$ cell produced rat BMP15 for cross-reactivity and $4=$ transfected $293 \mathrm{H}$ cell produced mouse GDF9 as a positive control. 


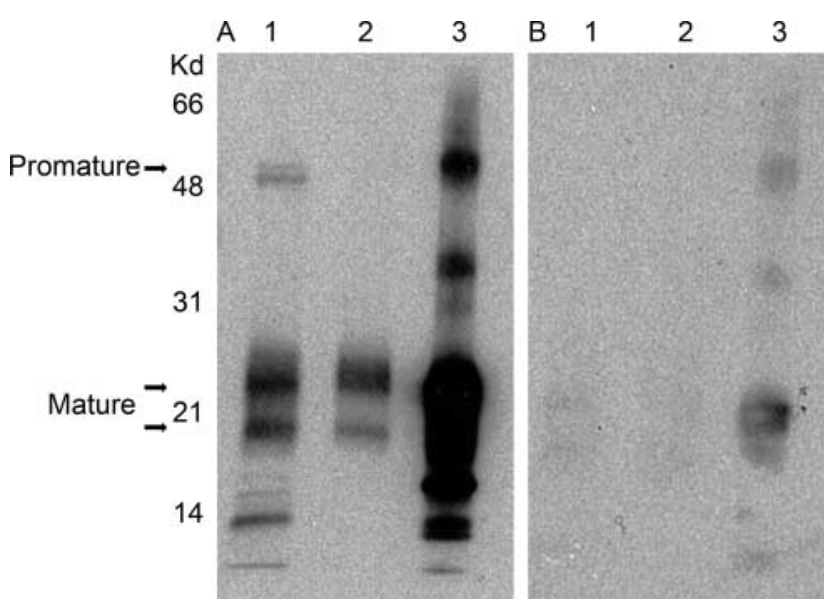

Figure 6 Western immunoblots of GDF9 in (A) ovine oocyte lysate and incubation medium and (B) after the GDF9 antibody (Mab37A) was preadsorbed with an ovine $E$. coli-derived GDF9 protein. Molecular sizes are indicated on the left of (A). Lanes are as follows: $1=$ oocyte lysate, $2=$ medium in which oocytes were incubated, and $3=293 \mathrm{H}$ cell produced ovine GDF9 as a positive control.

threefold increase in thymidine incorporation in sheep GC, only immuno-neutralisation of GDF9, and not BMP15, inhibited thymidine uptake. It could be argued that the failure of the BMP15 antibody to neutralise rat oocyte-derived BMP15 was due to the low sequence homology (i.e. 27\%) between the rat BMP15 mature protein and the MAB (Mab61A) used in this study. However, this seems unlikely to be the case as Mab61A was effective at blocking the effect of recombinant rBMP15 on ${ }^{3} \mathrm{H}$-thymidine uptake by rat GC exposed to both recombinant rBMP15 and oGDF9; in this experiment, recombinant rBMP15 or oGDF9 alone was unable to stimulate ${ }^{3} \mathrm{H}$-thymidine uptake by rat GC. As GDF9 and BMP15 were the only factors investigated, it is not possible to rule out critical roles for other putative oocyte-derived growth factors such as BMP6 or FGF8 (Juengel et al. 2006, Sugiura et al. 2007).

It is worth noting that there was considerable variation in ${ }^{3} \mathrm{H}$-thymidine uptake by GC between individual rat and sheep DO-GC co-incubation experiments when oocyte numbers were titrated. This is likely to be due to at least three factors that are not able to be controlled. The first relates to the fact that at any moment in time, no two follicles are likely to be functionally identical (McNatty et al. 2010), resulting in each DO pool containing functionally variable populations of DO. This was in contrast to the GC component in the co-incubation studies where identical aliquots of a pooled preparation of GC were added to all the incubation wells. In light of this, the second uncontrolled factor relates to the synergistic effects of GDF9 and BMP15. Previous studies show that very small changes in the level of recombinant BMP15 relative to GDF9 protein, or vice versa, can cause large changes (e.g. sevenfold) in ${ }^{3} \mathrm{H}$-thymidine uptake by GC (McNatty et al. 2005a). A third contribution to the variability observed in the present experiments is likely to be due to the relative proportions of healthy and degenerate oocytes recruited for study. While obviously degenerate oocytes were removed before denuding, no other criteria were used for exclusion. However, it is known that when the health of follicles based on GC criteria is assessed, BMP15 and GDF9 mRNA are significantly lower in atretic compared with healthy follicles (Crawford et al. 2011). Moreover, Lanuza et al. (1998) have reported that poor quality bovine oocytes are less effective than good quality oocytes in stimulating ${ }^{3} \mathrm{H}$-thymidine uptake by rat GC.

The immuno-neutralisation experiments established that of the two specific growth factors tested, ovine GC require both ovine GDF9 and ovine BMP15 to stimulate thymidine incorporation in contrast to rat GC, which

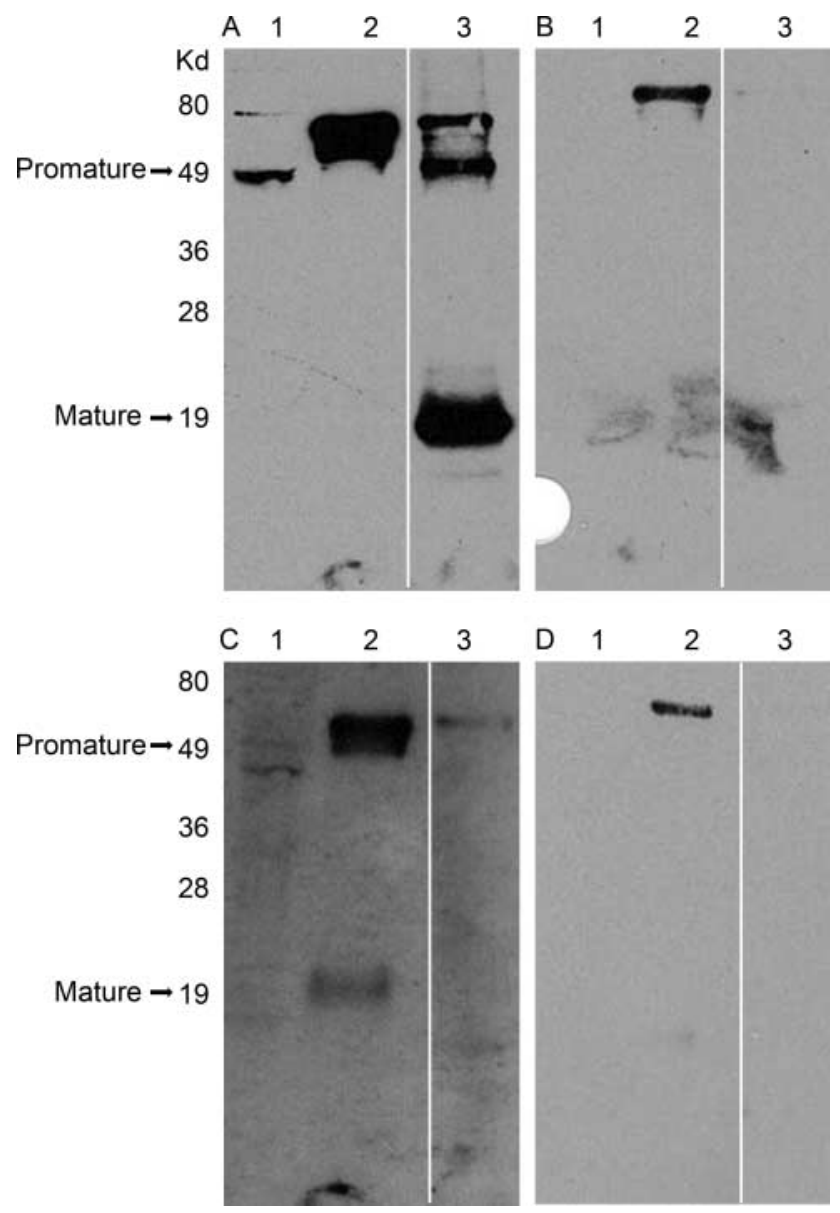

Figure 7 Western immunoblots of BMP15 in (A and C) rat oocyte lysate and (B and D) after the BMP15 antibodies (Mab61A in B and Mab3A/A in D) were preadsorbed with E. coli-produced ovine BMP15 and mouse BMP15 for Mab61A and Mab3A/A respectively. Molecular sizes are indicated on the left of $(\mathrm{A})$ and $(\mathrm{C})$. Lanes are as follows: $1=$ oocyte lysate, $2=$ transfected $293 \mathrm{H}$ cell-produced rat BMP15-positive control and $3=$ transfected $293 \mathrm{H}$ cell-produced ovine BMP15 as a positive control. The high MW bands in the preadsorbed blots B \& D were not identified. The separation of lanes $2 \& 3$ in all figures indicates the excision of a lane for a protein not relevant to this study. 


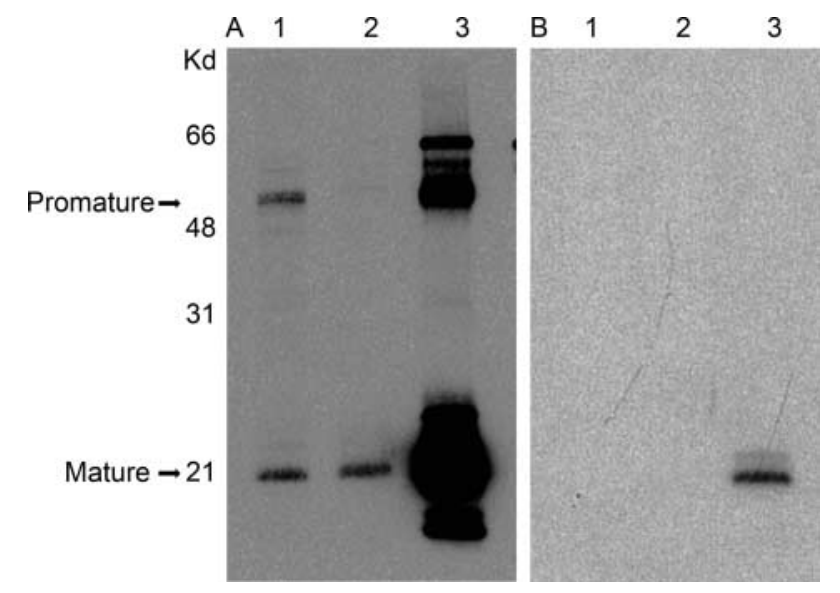

Figure 8 Western immunoblots of BMP15 in (A) ovine oocyte lysate and medium in which oocytes were incubated (incubation medium) and (B) after the BMP15 antibody (Mab61A) was preabsorbed with an ovine E. coli-derived BMP15 protein. Molecular sizes are indicated on the left of Fig. 7(A). Lanes are as follows: $1=$ oocyte lysate, $2=$ incubation medium and $3=293 \mathrm{H}$-produced ovine BMP15 as a positive control

require rat GDF9 but not rat BMP15. This interpretation is consistent with our hypothesis, namely, that there is no effect of BMP15 immuno-neutralisation on thymidine incorporation by rat or sheep GC co-incubated with rat DO due to species of origin of the growth factors (McNatty et al. 2005b). It is also consistent with the recent report by Simpson et al. (2012) which showed that there are species differences in the bioactivity of GDF9 due to different amino acid residues at key positions with respect to receptor binding domains. For example, through site-specific mutagenesis, they report that the Gly ${ }^{391}$ residue in the mature domain in human GDF9 confers latency whereas in mouse and rat GDF9, the 391 residue is Arg instead of Gly, which presents GDF9 in an active form. Interestingly, ovine GDF9 contains the Gly residue at 391, indicating that ovine GDF9 is not biologically active. In this and previous studies, we have reported that recombinant oGDF9 was not biologically active in stimulating ${ }^{3} \mathrm{H}$-thymidine uptake by rat GC (McNatty et al. 2005a).

It was of interest to note that the stimulatory effects of ovine DO on rat GC could be inhibited in part, by the BMP15 antibody indicating that BMP15 is capable of stimulating thymidine incorporation in the rat when present with oocyte-derived GDF9 in the incubation media. This is consistent with previous reports that ${ }^{3} \mathrm{H}$-thymidine uptake rat GC can be stimulated by recombinant human BMP15 in vitro (Otsuka et al. 2000, Moore et al. 2003, McMahon et al. 2008). However, we cannot exclude the possibility that the recombinant rBMP15 used may differ in bioactivity from endogenous rat BMP15. In addition, it is not possible to completely rule out the existence of trace levels of rat BMP15 in the co-incubation media as unprocessed promature BMP15 was detected in rat oocyte lysates, although not in the media. Recent studies by McIntosh et al. (2012) demonstrated that immuno-neutralisation of the proregion of mouse BMP15 significantly reduced both ovulation rate and litter size of mice, suggesting that even secreted forms of promature BMP15 have a biological role. However, as mentioned above, the roles of other oocyte-secreted factors cannot be discounted.

Promature and/or mature forms of GDF9 were present in oocyte lysates from rats and sheep. In both these species, fully processed monomeric forms of GDF9 were present in the incubation media. With respect to BMP15, oocyte lysates from sheep contained both promature and mature forms of the protein with a secreted fully processed mature form in the incubation media.

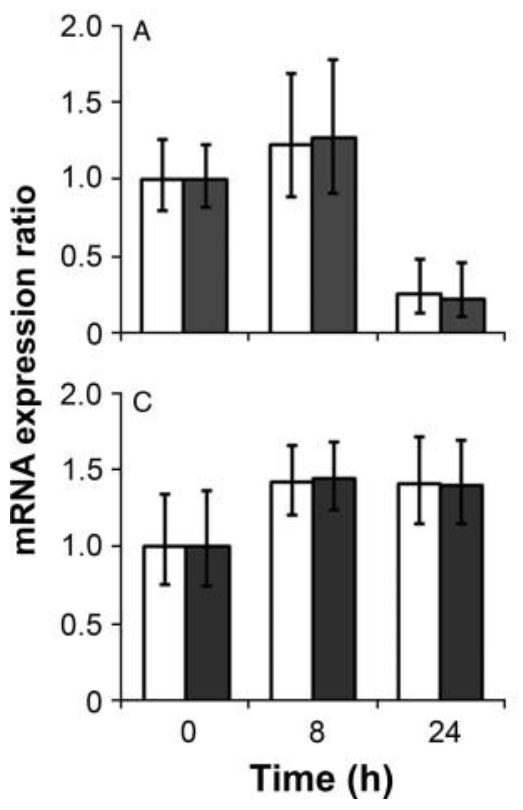

Reproduction (2012) 144 557-567

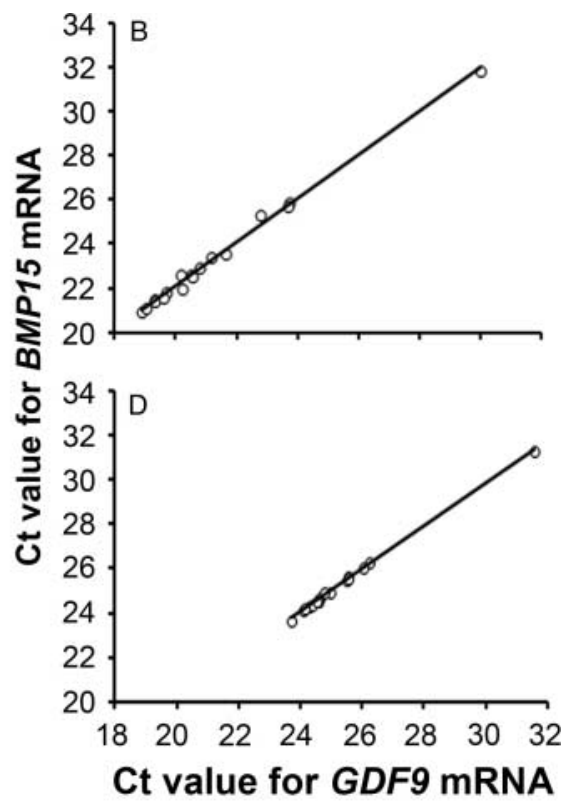

Figure 9 Effect of incubation time on GDF9 (white) and BMP15 (grey) mRNA levels in denuded oocytes (DO) of (A) rats and (C) sheep after co-incubation with granulosa cells (GC) from the same species $(n=3$ for both rat and sheep experiments). Regression plots of cycle threshold (Ct) values and lines of best fit for BMP15 and GDF9 genes from individual rat (B) DO co-incubated with rat GC and (D) ovine DO co-incubated with ovine $\mathrm{GC}$ for 0,8 or $24 \mathrm{~h}$. The histograms represent the mean \pm S.E.M. The mean GDF9 and BMP15 mRNA values at $24 \mathrm{~h}$ compared to those at $0 \mathrm{~h}$ approached significance (GDF9, $P=0.050 ; B M P 15, P=0.052$ ). The Ct correlation coefficients for both rat and sheep were 0.99 . 
In contrast, in the rat using the same antibody (Mab61A), a BMP15 promature form was present in the oocyte lysate, but there was no evidence of mature forms in either oocyte lysate or 293-derived recombinant rBMP15 control. No evidence was found for any secreted form of BMP15 in the incubation media notwithstanding the presence of very large numbers of oocytes in the incubation media (data not shown). Using an alternative MAB (Mab3A/A) that recognises both the promature and the mature forms of recombinant rBMP15, only trace levels of promature but not mature forms of BMP15 were identified in rat oocyte lysates. Using the Mab3A/A antibody, there was also no evidence that rat oocytes secreted any form of BMP15 into the media (data not shown). Of interest is that the predominant form of recombinant rBMP15 was the promature protein. When this preparation of rat BMP15 was added with ovine GDF9, the two proteins together enhanced thymidine uptake by rat GC. This finding is consistent with that reported by McIntosh et al. (2008), demonstrating a role for the proregion of BMP15 in the co-operative actions of GDF9 and BMP15 on rodent GC.

Overall, the results from the western blotting studies suggest that, compared with sheep, rat oocytes secrete relatively little BMP15. This interpretation is further supported by the preadsorption experiments whereby the addition of BMP15 antibodies did not reduce the increase in thymidine incorporation by rat GC after the addition of rat DO.

It could also be argued that the reason why rat oocytes secreted insufficient BMP15, not withstanding the large numbers of oocytes, arose from a decline in Bmp 15 mRNA expression levels by the end of the incubation period. However, the lower mean Bmp15 mRNA levels after $24 \mathrm{~h}$ were matched by an equivalent decline in Gdf9 mRNA levels, yet there was sufficient GDF9 in the spent media to stimulate thymidine incorporation in rat GC as the GDF9 effect could be neutralised by the addition of a GDF9 MAB. In contrast to the rat, there was no change in GDF9 and BMP15 mRNA expression in DO from sheep at the end of the incubation period. However, perhaps of greater significance in this regard were the relative mRNA expression ratios of GDF9 and BMP15 in the two species. In sheep, the relative mRNA expression levels of GDF9 were equivalent to those of BMP15 whereas in the rat the relative mRNA expression levels of Gdf9 were 4.3-fold greater than those of Bmp15. Thus, it seems reasonable to propose that a key difference between oocytes in the two species is that BMP15 and GDF9 mRNA are expressed in equivalent amounts in sheep, resulting in the secretion of appreciable amounts of both proteins, whereas in rats the relative mRNA expression levels of Bmp15 are low compared with Gdf9, resulting in appreciable amounts of GDF9 but limited amounts of mature BMP15 being secreted. In this study, the gene expression data were generated from pools of sheep or rat oocytes.
Nevertheless, the results are consistent with previous reports based on expression levels in individual oocytecumulus cell complexes and DO (Crawford et al. 2011, Crawford \& McNatty 2012).

The results from this study also support the in vivo findings by Crawford \& McNatty (2012) by demonstrating that the mRNA expression levels of GDF9 and BMP15 in DO of sheep and rats in vitro are also strongly associated. In vivo, the Gdf9:Bmp15 expression ratios are tightly regulated and differ across a wide rage of species (e.g. mouse, cattle, pig and deer; Crawford \& McNatty 2012). Linear regression analyses of both the sheep and the rat DO also show that the expression ratios of GDF9:BMP15 remain unchanged over the incubation period. While the removal of the cumulus cells was necessary to standardise the testing of effects of oocytes on GC thymidine incorporation, it is reasonable to suppose that removal of the somatic cells may compromise the functional state of the oocytes incubated in vitro, as was observed for the rat. Under normal physiological conditions, the expression levels of BMP15 and GDF9 in healthy ovine follicles between 1 and $5 \mathrm{~mm}$ in diameter are not related to antral follicular development (Crawford et al. 2011).

This in vitro study confirms and extends our understanding of the species differences in the relative roles of GDF9 and BMP15. This study also supports the hypothesis that in vivo, in a low ovulation rate species such as sheep, oocytes express levels of BMP15 mRNA equivalent to or greater than that of GDF9 and secrete biologically active levels of BMP15 protein. They also support the notion that during follicular growth, both GDF9 and BMP15 are required to promote cell proliferation in a low ovulation rate species. By contrast, in a high ovulation rate species such as the rat, Gdf9 mRNA is expressed at relatively higher levels than Bmp15 mRNA and little, if any, BMP15 protein is secreted at least until the preovulatory LH surge.

\section{Materials and Methods}

In order to compare the possible roles of oocyte-derived GDF9 and BMP15 on GC activity, the number of DO was titrated against a fixed number of GC. This determined the optimal number of DO that caused a significant uptake of ${ }^{3} \mathrm{H}$-thymidine, as a measure of DNA synthesis, in GC of both species. This optimal DO number was then used for subsequent immuno-neutralisation and gene expression studies. For the western blotting studies, the numbers of oocytes recovered were 100-500 per $50 \mu$ l of incubation media.

\section{Oocyte collection}

Ovaries from pre-pubertal ewe lambs were collected from the slaughterhouse (Taylor Preston, Ngauranga, Wellington, New Zealand) and transported on ice to the laboratory. Thereafter, at room temperature, the ovaries were trimmed of oviductal 
Table $1 \mathrm{~A}$ and B: probe sequences used in rat and sheep multiplex QPCR.

\begin{tabular}{ll}
\hline Gene & \\
\hline $\begin{array}{l}\text { (A) Rat } \\
\text { Rpl19 }\end{array}$ & [Cy5]CCAATGCCAACTCTCGTCAACAGATCAGGAAG[BHQ3] \\
Gdf9 & [6FAM]CACTCTGAACAACTCCGCTGCTTCCTCCT[BHQ1] \\
Bmp15 & [HEX]CACTGTGGTCTACCGCCATCAACTTCATCTAGT[BHQ1] \\
(B) Sheep & \\
RPL19 & [CY5]TTCTCATCCTCCTCATCCACGTTACCTTCTCGG[BHQ3] \\
GDF9 & [6FAM]AGTCTCAGCCTCAGATTCCAACGCAGTCCTA[BHQ1] \\
BMP15 & [HEX]AGAATGTCCCTCAGCCTTCCTGTGTCCCT[BHQ1] \\
\hline
\end{tabular}

tissue, washed in a $3 \%(\mathrm{v} / \mathrm{v})$ bleach-PBS $(0.15 \mathrm{M}, \mathrm{pH} 7.4$; PBS) solution and then rinsed twice with PBS. The ovaries were kept immersed in the PBS solution during oocyte collection. Twenty-one-day-old, pre-pubertal female Sprague-Dawley rats were killed by asphyxiation with $\mathrm{CO}_{2}$ gas (as approved by the VUW animal ethics committee) and the ovaries were collected into Leibovitz media (Invitrogen New Zealand Ltd). Ovaries were then trimmed from the connective tissues. Thereafter, both rat and sheep cumulus cell-oocyte complexes were recovered by puncturing follicles with a $20 \mathrm{~g}$ needle fitted to a 3 or $5 \mathrm{ml}$ syringe. Oocytes were mechanically denuded of their cumulus cells by repeated aspiration through a fine Pasteur pipette and/or vortexing the complexes for 10- to 20-s intervals up to 4-min duration.

\section{GC collection and preparation}

Rat GC were pooled following the aspiration of the intrafollicular contents from multiple antral follicles. Ovine GC were pooled following their recovery from dissected antral follicles of $\leq 4 \mathrm{~mm}$ diameter. No selection criteria were used to determine whether GC were recovered from healthy or atretic follicles. The GC were washed once in Leibovitz and then in M199 media (Sigma-Aldrich) and the cell viability determined. In the oocyte dose response experiments, 20000 live GC were co-incubated with $0,8,32$ or 64 DO of the same species and across species. In the growth factor neutralisation experiments, a total of 20000 GC were co-incubated with 32 DO.

\section{Thymidine incorporation assays}

All cell incubations were carried out at $37^{\circ} \mathrm{C}$ under $5 \% \mathrm{CO}_{2}$ in air with $95 \%$ humidity. For the oocyte titration experiments, the appropriate number of DO and 20000 live GC were transferred into 96-well plates in 30 and $20 \mu \mathrm{l}$ of M199 media respectively and incubated for $16 \mathrm{~h}$. Thereafter, the levels of ${ }^{3} \mathrm{H}$-thymidine incorporation were measured over a 6 -h interval as described previously (McNatty et al. 2005a). For the neutralisation experiments, $30 \mu \mathrm{l}$ of M199 media containing 32 DO were added to each test well together with $5 \mu$ of the appropriate antibody. The addition of $20 \mu \mathrm{l}$ of M199 media containing $20000 \mathrm{GC}$ resulted in a final volume of $55 \mu \mathrm{l} /$ well. The antibodies tested were MABs specific for either GDF9 (Mab47B) or BMP15 (Mab61A, Mab3A/A) or a control MAB against a nematode antigen (MabPAB1). Control wells containing DO with GC but no antibody or GC without DO were included in each incubation experiment. The Mab47B antibody was made against the ovine GDF9 mature protein sequence SEYFKQFLFPQNEC, which has $100 \%$ sequence homology with mice. This sequence also has a $93 \%$ homology with the corresponding rat sequence (SEYFRQFLFPQNEC). Moreover, this antibody has previously been used for immunoneutralisation studies of GDF9 in vitro and the antibody does not cross-react with BMP15 (Mclntosh et al. 2008). The Mab61A antibody against BMP15 was generated after immunization of mice against an E. coli-derived sheep BMP15 mature protein and found to be effective in immunoneutralisation studies in sheep and not to cross-react with GDF9 (McNatty et al. 2005a). From peptide mapping studies, the $M A B$ appears to be directed against an N-terminal sequence on the mature protein sequence, QAGSIASEVPGPSR (unpublished data; amino acid differences in bold). This sequence has a $64 \%$ homology with the corresponding rat BMP15 sequence, QTCSIASDVPCPSQ (amino acid differences are in bold). However, there are four homologous amino acids in a row (italicised) and previous studies with BMP15 and GDF9 antibodies indicate that a $27 \%$ homology can be sufficient for antibody recognition of ligand (McNatty et al. 2007). To validate the efficacy of the Mab61A antibody to immuno-neutralise rat BMP15, a 293-derived recombinant oGDF9 (66 ng/ml; McNatty et al. 2005a) and 293-derived recombinant $\mathrm{rBMP15}(6.5 \mathrm{ng} / \mathrm{ml})$ were either added alone or together with rat GC: these experiments were performed without antibody, with the control (PAB1) antibody $(3.4 \mu \mathrm{g} / \mathrm{ml})$ or with Mab61A $(3.4 \mu \mathrm{g} / \mathrm{ml})$ as described earlier $(n=4$ replicate experiments). In all experiments involving measures of ${ }^{3} \mathrm{H}$-thymidine incorporation, the method used has been described in detail elsewhere (McNatty et al. 2005a).

\section{Western blotting}

The western blotting technique for the GDF9 and BMP15 proteins has been described in detail elsewhere (Mclntosh et al. 2008). The samples (100-500 rat or sheep oocytes) were incubated for $24 \mathrm{~h}$ at a concentration of $\geq 2$ oocytes/ $\mu \mathrm{l}$. Thereafter, the incubation media devoid of oocytes were collected into $0.2 \mathrm{ml} \mathrm{PCR}$ tubes and $50 \mu \mathrm{l}$ of fresh M199 media were added to the oocytes. Both the incubation media

Table 2 Forward and reverse primer concentration in nanomolar for rat and sheep multiplex QPCR.

\begin{tabular}{lccccc}
\hline & & Rat & & Sheep \\
\cline { 2 - 5 } Gene & Forward & Reverse & Probe & Forward \\
GDF9 & 200 & 100 & 100 & 200 & Reverse \\
BMP15 & 300 & 200 & 100 & 200 & 200 \\
RPL19 & 300 & 200 & 100 & 200 & 200 \\
\hline
\end{tabular}


and the oocyte lysate samples contained a 25-fold dilution of the protease inhibitor cocktail (Roche Diagnostics) and were stored at $-20^{\circ} \mathrm{C}$ until processing. For these experiments, the MABs Mab37A and Mab47B were used to detect GDF9 in sheep and rat experiments respectively. The Mab37A antibody has previously been shown to be specific to ovine GDF9 (McNatty et al. 2005a). For the detection of BMP15 in both sheep and rat experiments, Mab61A antibody was used. The ability of Mab61A to recognise rat BMP15 protein was also tested using another MAB, Mab3A/A (generously supplied by Dr N Groome, Oxford Brookes University, Oxford, UK). This antibody was raised against a 29 amino acid sequence at the c-terminus end of human BMP15. This sequence shares an $83 \%$ homology with rat BMP15. The amino acid sequences are VPYKYVPISVLMIEANGSILYKEYEGMIA (human BMP15) and VPYKFLPMSILLIEANGSILYKEYEGMIA (rat BMP15; the amino acid differences are indicated in bold). Mab3A/A has routinely been used in our laboratory to detect mouse BMP15 (Reader et al. 2011) and shares a 93\% homology with rat BMP15 (VPYNFLPMSILLIETNGSILYKEYEGMIA; mouse sequence; the amino acids that differ to the rat sequence are indicated in bold). For the GDF9 reference standard, a $293 \mathrm{H}$ cell-derived ovine GDF9 was used as a positive control. For the blocking experiments, an E. coli-derived ovine GDF9 mature protein was used. For ovine BMP15, the reference standard was a $293 \mathrm{H}$ cell-derived ovine BMP15 and for the ovine blocking experiment, E. coli-derived ovine BMP15 mature protein was used. For the rat BMP15 studies, both a $293 \mathrm{H}$ cell-derived rat BMP15 and a 293H cell-derived ovine BMP15 were used as reference standards and blocking was performed with either an E coli-derived ovine BMP15 or a mouse BMP15 preparation (McNatty et al. 2005a, Mclntosh et al. 2008).

\section{Analyses of GDF9 and BMP15 mRNA}

The multiplex qPCR methodology used in this study has been described in detail by Crawford et al. (2011). Total RNA from frozen pools of 32 oocytes per time point $(n=5-6)$ was extracted using the ArrayPure Nanoscale RNA purification kit (Epicentre Biotechnologies, Madison, WI, USA) according to the manufacturer's instructions. An in-house $0.1 \mathrm{M}$ Tris- $\mathrm{HCl}$ buffer with 0.5 M EDTA ( $\mathrm{pH}$ 8.0) was used to reconstitute the precipitated total RNA. All other specialised reagents were supplied in the kit. The synthesis of cDNA was carried out with the SuperScript Vilo cDNA Synthesis Kit (Invitrogen) following the manufacturer's instructions. The primer and probe sequences for rat and sheep are shown in Table 1, and their optimised concentrations are shown in Table 2. The efficiencies for each qPCR reaction were $\geq 93 \%$. Quantification of samples using the $\Delta \Delta C T$ method (Livak \& Schmittgen 2001) has been reported elsewhere (Crawford et al. 2011). The expression levels of GDF9 and BMP15 in the DO were relative to a calibrator sample (cDNA from a rat or ovine ovary). Although the housekeeping gene (RPL19) was included in every triplex reaction, the values were not corrected for RPL19 but expressed as total expression of oocyte GDF9 or BMP15. The ratios of GDF9:BMP15 mRNA in individual oocytes was calculated by $1: 2^{-(\text {CtGDF9-CtBMP15) }}$.

\section{Statistical analyses}

For the ${ }^{3} \mathrm{H}$-thymidine uptake studies, the results from individual experiments were averaged and a one-way ANOVA was performed. If differences were observed from ANOVA, the Bonferroni's post-hoc test was used to test for differences between individual group means. If the data were not normally distributed, they were naturally log-transformed before analyses. For non-normally distributed data, the Kruskal-Wallis non-parametric test was also undertaken. Means that differed by $P<0.05$ were considered to be significantly different from one another. For the antibody immuno-neutralisation studies, the means for the incubations without antibody (no antibody control) were arbitrarily assigned a value of 1 . Thereafter, the fold change for every GDF9 or BMP15 antibody treatment relative to the no antibody control was compared to the foldchange for the non-specific antibody control using the Student's $t$-test. To examine the relationship between the relative expression levels for GDF9 and BMP15 mRNA, the cycle threshold $(\mathrm{Ct})$ values for each oocyte was subjected to linear regression analyses.

\section{Declaration of interest}

The authors declare that there is no conflict of interest that could be perceived as prejudicing the impartiality of the research reported.

\section{Funding}

This research was supported by the New Zealand Foundation for Research, Science and Technology (C10X0308), the Royal Society of New Zealand Marsden Fund (08-VUW-010) and an AgResearch PhD Scholarship to J Lin.

\section{Acknowledgements}

The authors wish to thank Prof. Sue Schenk and Mr Richard Moore (Department of Psychology, Victoria University of Wellington) for the supply of rats used in these experiments and the staff at Taylor Preston Meatworks, Wellington, for the supply of sheep ovaries. They also wish to thank Prof. Olli Ritvos (University of Helsinki, Finland) for the transfected 293H cell lines and Mr Steve Lawrence and Ms Andrea Western for the supply of the recombinant E. coli and 293H-derived GDF9 and BMP15 proteins.

\section{References}

Crawford JL \& McNatty KP 2012 The ratio of growth differentiation factor 9: bone morphogenetic protein $15 \mathrm{mRNA}$ expression is tightly co-regulated and differs between species over a wide range of ovulation rates. Molecular and Cellular Endocrinology 348 339-343. (doi:10.1016/ j.mce.2011.09.033)

Crawford JL, Heath DA, Reader KL, Quirke LD, Hudson NL, Juengel JL \& McNatty KP 2011 Oocytes in sheep homozygous for a mutation in bone morphogenetic protein receptor $1 \mathrm{~B}$ express lower mRNA levels of bone morphogenetic protein 15 but not growth differentiation factor 9 . Reproduction 142 53-61. (doi:10.1530/REP-10-0485) 
Di Pasquale E, Beck-Peccoz P \& Persani L 2004 Hypergonadotropic ovarian failure associated with an inherited mutation of human bone morphogenetic protein-15 (BMP15) gene. American Journal of Human Genetics 75 106-111. (doi:10.1086/422103)

Dong J, Albertini DF, Nishimori K, Kumar TR, Lu N \& Matzuk MM 1996 Growth differentiation factor-9 is required during early ovarian folliculogenesis. Nature 383 531-535. (doi:10.1038/383531a0)

Dube JL, Wang P, Elvin J, Lyons KM, Celeste AJ \& Matzuk MM 1998 The bone morphogenetic protein 15 gene is $X$-linked and expressed in oocytes. Molecular Endocrinology 12 1809-1817. (doi:10.1210/me.12. 12.1809)

Feary ES, Juengel JL, Smith P, French MC, $\mathrm{O}^{\prime}$ Connell AR, Lawrence SB, Galloway SM, Davis GH \& McNatty KP 2007 Patterns of expression of messenger RNAs encoding GDF9, BMP15, TGFB1, BMPR1B and $B M P R 2$ during follicular development and characterization of ovarian follicular populations in ewes carrying the Woodlands $\mathrm{Fec} X 2^{\mathrm{W}}$ mutation. Biology of Reproduction 77 990-998. (doi:10.1095/biolreprod.107. 062752)

Galloway SM, McNatty KP, Cambridge LM, Laitinen MP, Juengel JL, Jokiranta TS, McLaren RJ, Luiro K, Dodds KG, Montgomery GW et al. 2000 Mutations in an oocyte-derived growth factor gene (BMP15) cause increased ovulation rate and infertility in a dosage-sensitive manner. Nature Genetics 25 279-283. (doi:10.1038/77033)

Gilchrist RB, Ritter LJ, Cranfield M, Jeffery LA, Amato F, Scott SJ, Myllymaa S, Kaivo-Oja N, Laitinen H, Mottershead DG et al. 2004 Immunoneutralization of growth differentiation factor 9 reveals it partially accounts for mouse oocyte mitogenic activity. Biology of Reproduction 71 732-739. (doi:10.1095/biolreprod.104.028852)

Gilchrist RB, Ritter LJ, Myllymaa S, Kaivo-Oja N, Dragovic RA, Hickey TE, Ritvos O \& Mottershead DG 2006 Molecular basis of oocyte-paracrine signalling that promotes granulosa cell proliferation. Journal of Cell Science 119 3811-3821. (doi:10.1242/jcs.03105)

Hanrahan JP, Gregan SM, Mulsant P, Mullen M, Davis GH, Powell R \& Galloway SM 2004 Mutations in the genes for oocyte-derived growth factors GDF9 and BMP15 are associated with both increased ovulation rate and sterility in Cambridge and Belclare sheep (Ovis aries). Biology of Reproduction 70 900-909. (doi:10.1095/biolreprod.103.023093)

Hashimoto O, Moore RK \& Shimasaki S 2005 Posttranslational processing of mouse and human BMP-15: potential implication in the determination of ovulation quota. PNAS 102 5426-5431. (doi:10.1073/pnas.0409 533102)

Jaatinen R, Laitinen MP, Vuojolainen K, Aaltonen J, Louhio $\mathrm{H}$, Heikinheimo K, Lehtonen E \& Ritvos O 1999 Localization of growth differentiation factor-9 (GDF-9) mRNA and protein in rat ovaries and cDNA cloning of rat GDF-9 and its novel homolog GDF-9B. Molecular and Cellular Endocrinology 156 189-193. (doi:10.1016/S0303-7207 (99)00100-8)

Juengel JL \& McNatty KP 2005 The role of proteins of the transforming growth factor- $\beta$ superfamily in the intraovarian regulation of follicular development. Human Reproduction Update 11 144-161. (doi:10.1093/ humupd/dmh061)

Juengel JL, Hudson NL, Heath DA, Smith P, Reader KL, Lawrence SB, O'Connell AR, Laitinen MP, Cranfield M, Groome NP et al. 2002 Growth differentiation factor 9 and bone morphogenetic protein 15 are essential for ovarian follicular development in sheep. Biology of Reproduction 67 1777-1789. (doi:10.1095/biolreprod.102.007146)

Juengel JL, Reader KL, Bibby AH, Lun S, Ross I, Haydon LJ \& McNatty KP 2006 The role of bone morphogenetic proteins 2,4,6 and 7 during ovarian follicular development in sheep: contrast to rat. Reproduction 131 501-513. (doi:10.1530/rep.1.00958)

Lanuza GM, Fischman ML \& Baranao JL 1998 Growth promoting activity of oocytes on granulosa cells is decreased upon meiotic maturation. Developmental Biology 197 129-139. (doi:10.1006/dbio. 1998.8865)

Livak KJ \& Schmittgen TD 2001 Analysis of relative gene expression data using real-time quantitative PCR and the $2^{-\Delta \Delta C t}$ method. Methods 25 402-408. (doi:10.1006/meth.2001.1262)

McIntosh CJ, Lun S, Lawrence S, Western AH, McNatty KP \& Juengel JL 2008 The proregion of mouse BMP15 regulates the cooperative interactions of BMP15 and GDF9. Biology of Reproduction 79 889-896. (doi:10.1095/biolreprod.108.068163)
McIntosh CJ, Lawrence S, Smith P, Juengel JL \& McNatty KP 2012 Active immunization against the proregions of GDF9 or BMP15 alters ovulation rate and litter size in mice. Reproduction 143 195-201. (doi:10.1530/ REP-11-0336)

McMahon HE, Hashimoto O, Mellon PL \& Shimasaki S 2008 Oocytespecific overexpression of mouse bone morphogenetic protein-15 leads to accelerated folliculogenesis and early onset of acyclicity in transgenic mice. Endocrinology 149 2807-2815. (doi:10.1210/en.2007-1550)

McNatty KP, Moore LG, Hudson NL, Quirke LD, Lawrence SB, Reader K, Hanrahan JP, Smith P, Groome NP, Laitinen M et al. 2004 The oocyte and its role in regulating ovulation rate: a new paradigm in reproductive biology. Reproduction 128 379-386. (doi:10.1530/rep.1.00280)

McNatty KP, Juengel JL, Reader KL, Lun S, Myllymaa S, Lawrence SB, Western A, Meerasahib MF, Mottershead DG, Groome NP et al. 2005a Bone morphogenetic protein 15 and growth differentiation factor 9 cooperate to regulate granulosa cell function. Reproduction 129 473-480. (doi:10.1530/rep.1.0511)

McNatty KP, Juengel JL, Reader KL, Lun S, Myllymaa S, Lawrence SB, Western A, Meerasahib MF, Mottershead DG, Groome NP et al. 2005b Bone morphogenetic protein 15 and growth differentiation factor 9 cooperate to regulate granulosa cell function in ruminants. Reproduction 129 481-487. (doi:10.1530/rep.1.00517)

McNatty KP, Smith P, Moore LG, Reader K, Lun S, Hanrahan JP, Groome NP, Laitinen M, Ritvos O \& Juengel JL 2005c Oocyte-expressed genes affecting ovulation rate. Molecular and Cellular Endocrinology 234 57-66. (doi:10.1016/j.mce.2004.08.013)

McNatty KP, Hudson NL, Whiting L, Reader KL, Lun S, Western A, Heath DA, Smith P, Moore LG \& Juengel JL 2007 The effects of immunizing ewes with different BMP15 or GDF9 peptide sequences on ovarian follicular activity and ovulation rate. Biology of Reproduction $\mathbf{7 6}$ 552-560. (doi:10.1095/biolreprod.106.054361)

McNatty KP, Heath DA, Hudson NL, Reader KL, Quirke L, Lun S \& Juengel JL 2010 The conflict between hierarchical ovarian follicular development and superovulation treatment. Reproduction 140 287-294. (doi:10.1530/REP-10-0165)

Mester B, Bibby A, Crawford JL, McNatty KP, Juengel JL \& McIntosh CJ 2011 Spatio-temporal expression patterns on Bmp15 and Gdf9 mRNA in the mouse ovarian follicle. In Society for Reproduction and Fertility Annual Conference 2011 Abstract Book. Abstract 017. University of Sussex, Brighton, UK: Society for Reproduction and Fertility.

Moore RK, Otsuka F \& Shimasaki S 2003 Molecular basis of bone morphogenetic protein-15 signaling in granulosa cells. Journal of Biological Chemistry 278 304-310. (doi:10.1074/jbc.M207362200)

Moore RK, Erickson GF \& Shimasaki S 2004 Are BMP-15 and GDF-9 primary determinants of ovulation quota in mammals? Trends in Endocrinology and Metabolism 15 356-361. (doi:10.1016/j.tem.2004. 08.008)

Mottershead DG, Ritter LJ \& Gilchrist RB 2011 Signalling pathways mediating specific synergistic interactions between GDF9 and BMP15. Molecular Human Reproduction 18 121-128. (doi:10.1093/molehr/ gar056)

Otsuka F \& Shimasaki S 2002 A negative feedback system between oocyte bone morphogenetic protein 15 and granulosa cell kit ligand: its role in regulating granulosa cell mitosis. PNAS 99 8060-8065. (doi:10.1073/ pnas.122066899)

Otsuka F, Yao Z, Lee T, Yamamoto S, Erickson GF \& Shimasaki S 2000 Bone morphogenetic protein-15. Identification of target cells and biological functions. Journal of Biological Chemistry 275 39523-39528. (doi:10.1074/jbc.M007428200)

Otsuka F, McTavish KJ \& Shimasaki S. 2011 Integral role of GDF-9 and BMP-15 in ovarian function. Molecular Reproduction and Development 78 9-21. (doi:10.1002/mrd.21265)

Prochazka R., Nemcova L., Naqyova E. \& Kanka J. 2004 Expression of growth differentiation factor 9 messenger RNA in porcine growing and preovulatory ovarian follicles. Biology of Reproduction 71 1290-1295. (doi:10.1095/biolreprod.104.027912)

Reader KL, Heath DA, Lun S, McIntosh CJ, Western AH, Littlejohn RP, McNatty KP \& Juengel JL 2011 Signalling pathways involved in the co-operative effects of ovine and murine GDF9 and BMP15-stimulated thymidine uptake by rat granulosa cells. Reproduction 142 123-131. (doi:10.1530/REP-10-0490) 
Shimasaki S, Moore RK, Otsuka F \& Erickson GF 2004 The bone morphogenetic protein system in mammalian reproduction. Endocrine Reviews 25 72-0101. (doi:10.1210/er.2003-0007)

Simpson CM, Stanton PG, Walton KL, Chan KL, Ritter LJ, Gilchrist RB \& Harrison CA 2012 Activation of latent human GDF9 by a single residue change $\left(\right.$ Gly $\left.^{391} \mathrm{Arg}\right)$ in the mature domain. Endocrinology 153 1301-1310. (doi:10.1210/en.2011-1632)

Sugiura K, Su Y-Q, Diaz FJ, Pangas SA, Sharma S, Wigglesworth K, O'Brien MJ, Matzuk MM, Shimasaki S \& Eppig JJ 2007 Oocyte-derived BMP15 and FGFs cooperate to promote glycolysis in cumulus cells. Development 134 2593-2603. (doi:10.1242/dev.006882)

Vanderhyden BC, Telfer EE \& Eppig JJ 1992 Mouse oocytes promote proliferation of granulosa cells from preantral and antral follicles in vitro. Biology of Reproduction 46 1196-1204. (doi:10.1095/biolreprod46.6.1196)
Yan C, Wang P, DeMayo J, De Mayo FJ, Elvin JA, Carino C, Prasad SV Skinner SS, Dunbar BS, Dube JL et al. 2001 Synergistic roles of bone morphogenetic protein 15 and growth differentiation factor 9 in ovarian function. Molecular Endocrinology 15 854-866. (doi:10.1210/me.15.6.854)

Yoshino O, McMahon HE, Sharma S \& Shimasaki S 2006 A unique preovulatory expression pattern plays a key role in the physiological functions of BMP15 in the mouse. PNAS 103 10678-10683. (doi:10.1073/pnas.0600507103)

Received 27 October 2011

First decision 21 December 2011

Revised manuscript received 23 August 2012

Accepted 10 September 2012 